\title{
Security Sector Reform as a Contribution to Crime Pre- vention in South Eastern Europe
}

\author{
Istvan Gyarmati ${ }^{1}$
}

The radical changes in the world order over the past several years make the issue of dealing with organized crime both more important and at the same time so much more difficult. All that is happening against this background is tied to the events of September 11, just like the emergence of the previous world order was tied to the Treaty of Westphalia, which is basically a good tool to illustrate what these changes really were. Organized crime is all too well suited to these changes, unfortunately, and we cannot deal with it without addressing the changes in general.

The new world order is mainly characterized by the appearance of non-state actors who don't look like states, don't behave like states, and don't want to behave like states. Therefore, all the instruments at our disposal that were geared to dealing with states do not work when addressing these non-state actors.

The world has seen similar non-state actors before, but these actors, like the Catholic Church, or more recently the entities which have tried to gain independence from larger state structures-like the Nagorno Karabakhs, the Kosovos, and the Abkhazias of this world - have always had a desire to be viewed and treated as if they were states. And this is basically how the world treated these entities, an approach that wound up creating tremendous problems, but one that at least gave us some tools to deal with them.

With the new breed of non-state actors, such as organized crime or terrorism, these tools are no longer effective, since these entities have constituted themselves in direct opposition to these instruments. The desire of Kosovo or Nagorno Karabakh was to fit into the existing order of states, to be recognized as one of them. These new actors do not want to fit into this order-they want to destroy it, and this is a tremendous difference. There is a difference between organized crime and terrorism, however, because global terrorism wants to destroy the system as it is presently ordered, whereas organized crime wants to use the system to its advantage, thereby destroying it. But they are nevertheless natural allies, because they have very similar features and very similar objectives.

The collapse of the old world order — the Westphalian order, if you will—has many consequences, most of which I do not want to discuss here but which we will have to face in the decades to come. Just to name a few: the collapse of the nuclear non-proliferation regime, which we do not want to recognize, but which

\footnotetext{
${ }^{1}$ Dr. Istvan Gyarmati is Senior Advisor on South Eastern Europe at the Geneva Centre for the Democratic Control of Armed Forces, Geneva, Switzerland.
} 


\section{THE QUARTERLY JOURNAL}

is a fact; the crisis in trans-Atlantic relations; and the growing gap between public opinion and governments all over Europe, if not in all countries. But there is one consequence which is perhaps more important than these others, and that is the crisis of international law and international institutions. Because international laws and institutions were invented to deal with states, we now have to formulate ways to deal with non-state actors who are largely immune to legal constraints. The world cannot remain without remedies in the face of actors who love to violate legal restrictions, especially when these actors have powers which rival those of states, and will become even more powerful by acquiring weapons of mass destruction (in the case of international terrorism).

So we must face these new threats from non-state actors, including organized crime. There is almost a form of competition between organized crime and terrorism (which I think is the more dangerous phenomenon), but I do not think that we need to decide that one is more of a threat than the other. Ultimately, they do not compete; they are essentially allies who both provide support, in one form or another, for international terrorism.

Organized crime is a threat to the stability of any one state, especially to weak states. This line of argument is familiar, and weak states are the targets of organized crime for very understandable reasons. The existence of weak state structures makes criminal activity much less dangerous, as well as much more profitable. Last but not least, criminal organizations have a chance to hijack the state or state institutions, which they almost always manage to do in weak states, although with varying degrees of difficulty. The process of institution-building in states making the transition to democracy-and even more so in new states, or in territories which are not yet nation-states, where the nation-building process has not been concluded - is by necessity an open process, and this renders it very easy for organized crime to infiltrate the institution-building process and thereby become part of the institutions. And we see the results in cases where organized crime has penetrated or taken over the police or judiciary, or the intelligence or customs services. In these cases, organized crime is extremely difficult to fight, because one is essentially using criminals to try to fight organized crime. It becomes very difficult for different institutions to cooperate in the fight against organized crime, because in doing so they offer information to the targets. In most cases, if an outside intelligence service provides information to the police or the intelligence services of such a country, one can be assured that in the next day or the next hour the information will end up in the hands of those who are the targets of investigation.

Such a degree of criminal infiltration of state structures is of course a tremendous danger to democracy. It not only undermines democracy and democratic institutions, it undermines the public faith in democracy. It comes to appear that democracy equals chaos and crime. Under these conditions, the nostalgia for a 
more stable, regulated, safe regime, even at the cost of some political concessions, can grow.

Transitional economies essentially produce the labor force for organized crime. If you have tens of thousands of unemployed soldiers, policemen, and border guards in a country, all fully trained, this provides organized crime with the ability to recruit everybody and everything they need. And there is no way to avoid it. In the transition from authoritarian rule, tens of thousands of workers formerly employed by the state security apparatus will become unemployed.

Weak states (and poor states) have serious difficulties dealing with this problem. In addition, there is the threat this problem poses to the EU itself, because the more that the process of EU enlargement progresses, the greater the presence of organized crime within the EU. Unfortunately, I can tell you that it will happen with the very first wave of enlargement, coming from a country that will be part of this wave. But the more that enlargement progresses-especially if it happens fast, as many of us wish - the more the Schengen regime will become irrelevant. It will be much less difficult for the criminals to commute inside Schengen and outside Schengen, as state institutions that are already corrupted will simply become part of the Schengen regime.

An absolutely new approach is needed, but frankly it does not appear to be emerging. A new approach is needed because organized crime, especially when combined with international terrorism - and rest assured that, sooner or later, this combination will arise in South Eastern Europe as well—cannot be fought with police alone. And such an approach runs counter to the very basic principles of democracy as we have known them up to this point, namely that intelligence services and the army are not for internal use. But we will have to recognize-as the Americans are starting to recognize, although they have not yet fully worked it out - what will always be the case, which is that organized crime is not a police issue alone. Intelligence is extremely important in fighting organized crime, maybe even more important than police. Intelligence cooperation is very important, as is cooperation between different agencies. At some point in this struggle, paramilitary forces or even the military will be needed, and this is extremely dangerous to democracy as we know it and to human rights. It will be very difficult to find the right balance.

We can only hope that we will be able to find this balance between security and democratic values. But we can make two mistakes, and we are already making them. Human rights activists are fighting against extending the powers of intelligence services, and of course state bureaucrats are fighting for extending them, and there is no real compromise between the two.

Inter-agency intelligence cooperation, vertical governmental cooperation, and international cooperation will all be critical. This of course challenges many principles and practices from the past. States will have to give up additional parts of their sovereignty, but this is very difficult not only for political reasons; it is very 


\section{THE QUARTERLY JOURNAL}

difficult for newly emerged countries who regained (or gained) independence ten years ago to immediately give up important elements of their sovereignty. And this step represents the best possible weapon for nationalist forces to use against those governments.

But it is also difficult for more established states, like the EU countries and other democracies, to make it a two-way street. And in most cases their tendency is to keep it a one-way street, which will not work in the long run. They have good reasons to keep the flow of cooperation and information primarily going in only one direction because, as was mentioned above, information flowing to the institutions of a more compromised state finds a direct route to organized crime. But keeping the model of cooperation a one-way street will soon raise questions about the whole process in the eyes of those who only give information but do not receive.

Such cooperation is also a threat to established notions of privacy, because if databases of different agencies or of different countries are connected, privacy will be substantially eroded. It is also very difficult to fight organized crime because states do not like to admit that they have a problem, and societies like it even less. We have seen that most societies are in a state of denial regarding concrete forms of organized crime, and this is not typical only of South Eastern Europe. The new member states of the EU always take pride in the fact that they are different from SEE, that they do not have organized crime at all, although I could quote you examples where organized crime has penetrated governments in those countries. This is not to mention the older members of the EU, where you also have organized crime, although on a different scale.

It is also difficult for such states to detect organized crime because it often hides in state institutions, and those institutions will be the last to admit that organized crime is a problem, and that they are part of the problem, not part of the solution. In addition, as mentioned above, as soon as state institutions are dominated by criminals, the fight against them will be rendered extremely difficult, for very understandable reasons.

There also exists a huge contradiction between the legal situation and the reality on the ground. Most of these countries are hastily introducing legislation that meets or even exceeds EU standards, but if you look at the implementation of those laws and regulations, little has changed. There is a culture in many of these countries of not implementing laws, which comes from history, either from the Ottoman Empire, or from the Communist Empire, where you said one thing and did another. This is not seen as something bad-it is normal, it is part of life. So in many countries, you see beautiful legislation and terrible implementation. Given all the problems mentioned above, implementation will be extremely difficult, and the EU is making a huge mistake by looking only at legislation and not at implementation when making decisions about cooperation, enlargement, and other such matters. 
Last but not least is the phenomenon of corruption. Corruption opens the door to organized crime, because once you have corrupted a politician or a civil servant in the security sector, there is no way he or she can fight against organized crime. This is basically the way that organized crime has gone about ensuring political support, and nobody can deny that corruption has penetrated very high in the political life of these countries, which makes it even more difficult to fight.

When I don't know the answers to all my questions, I always quote Albert Einstein, who said that "the right question is already fifty percent of the answer," so I hope that I can take pride that I gave you fifty percent of the answer, and the other fifty percent should come from the rest of the world.

But that is not enough: we should find some answers. And I think the only answer is shaping a much more coherent, much more rigid approach to the problems of organized crime, terrorism, and corruption on the part of the EU, not only internally, but also with regard to the countries concerned. It is ultimately in the interests of these countries. It might delay their accession to EU membership by a few years, but I think it will do much more good than harm to them if it is done very coherently.

Institution-building should be the main focus of cooperation, and here I mean institution-building in very strict terms: controlling if and how much these institutions are penetrated by criminals. It can be done. In most cases, countries already know this about their institutions. Intelligence services from the outside basically know it as well, but out of politeness and out of misplaced perceptions of equality, they do not say anything about it, or say it in such a way that there are no consequences.

The other side of the coin is that we should not try to build many Netherlands in Bosnia, and we shouldn't try to build a mini EU in South Eastern Europe. These countries have very special histories and very special cultures that are to some extent different from the rest of Europe, and this must be taken into account. I am not suggesting that low salary levels are a justification for corruption, but we have to understand that, as a long as police officers cannot live on their salaries, they will always be more vulnerable to corruption and to supporting organized crime. And as long as politicians and ministers in these countries make $300 \mathrm{Eu}-$ ros a month, they will always be more vulnerable to corruption than those who make a little bit more. Transparency is also very important, a phenomenon which is not part of the traditions of these countries. I am not suggesting that increasing the salaries of policemen from 50 Euros to 500 Euros will immediately solve the problem. But the combination of increased salaries with very strong institutions, sincere cooperation from the outside, more transparency, and conditionality-not in terms of what we had before, which are conditions that are impossible to meet and easily forgotten, but establishing real conditions for assistance and then delivering the assistance once the conditions are met-in a long-term strategy could be very helpful to these countries and to Western Europe as well, because if we 
THE QUARTERLY JOURNAL

do not win the war against terrorism and organized crime in South Eastern Europe we will lose the war at home. 